\title{
Expression of phosphofructokinase in Neisseria meningitidis
}

\author{
Gino J. E. Baart, ${ }^{1,2} \uparrow$ Marc Langenhof, ${ }^{1,2}$ Bas van de Waterbeemd, ${ }^{1}$ \\ Hendrik-Jan Hamstra, ${ }^{1}$ Bert Zomer, ${ }^{1}$ Leo A. van der Pol, ${ }^{1}$ E. C. Beuvery, ${ }^{3}$ \\ Johannes Tramper $^{2}$ and Dirk E. Martens ${ }^{2}$
}

Correspondence

Gino J. E. Baart

gino.baart@ugent.be

Received 15 June 2009

Revised 26 September 2009

Accepted 1 October 2009

\author{
${ }^{1}$ Netherlands Vaccine Institute (NVI), Unit Research and Development, PO Box 457, 3720 AL \\ Bilthoven, The Netherlands \\ ${ }^{2}$ Wageningen University, Food and Bioprocess Engineering Group, PO Box 8129, 6700 EV \\ Wageningen, The Netherlands
}

${ }^{3}$ PAT consultancy, Kerkstraat 66, 4132 BG Vianen, The Netherlands

\begin{abstract}
Neisseria meningitidis serogroup B is a pathogen that can infect diverse sites within the human host. According to the N. meningitidis genomic information and experimental observations, glucose can be completely catabolized through the Entner-Doudoroff pathway and the pentose phosphate pathway. The Embden-Meyerhof-Parnas pathway is not functional, because the gene for phosphofructokinase (PFK) is not present. The phylogenetic distribution of PFK indicates that in most obligate aerobic organisms, PFK is lacking. We conclude that this is because of the limited contribution of PFK to the energy supply in aerobically grown organisms in comparison with the energy generated through oxidative phosphorylation. Under anaerobic or microaerobic conditions, the available energy is limiting, and PFK provides an advantage, which explains the presence of PFK in many (facultatively) anaerobic organisms. In accordance with this, in silico flux balance analysis predicted an increase of biomass yield as a result of PFK expression. However, analysis of a genetically engineered $N$. meningitidis strain that expressed a heterologous PFK showed that the yield of biomass on substrate decreased in comparison with a pfkA-deficient control strain, which was associated mainly with an increase in $\mathrm{CO}_{2}$ production, whereas production of by-products was similar in the two strains. This might explain why the $p f k A$ gene has not been obtained by horizontal gene transfer, since it is initially unfavourable for biomass yield. No large effects related to heterologous expression of $p f k A$ were observed in the transcriptome. Although our results suggest that introduction of PFK does not contribute to a more efficient strain in terms of biomass yield, achievement of a robust, optimal metabolic network that enables a higher growth rate or a higher biomass yield might be possible after adaptive evolution of the strain, which remains to be investigated.
\end{abstract}

tPresent address: Ghent University, Department of Plant Systems Biology/Department of Biology, Technologiepark 927, 9052 Ghent, Belgium.

Abbreviations: dcw, dry cell weight; ED, Entner-Doudoroff; EMP, Embden-Meyerhof-Parnas; F6P, fructose 6-phosphate; FBA, flux balance analysis; FR, fold ratio; HGT, horizontal gene transfer; LP, linear programming; MCS, Monte Carlo simulation; NVI, Netherlands Vaccine Institute; PEP, phosphoenolpyruvate; PP, pentose phosphate, PTS system, phosphotransferase system.

The microarray data discussed in this paper are available under GEO accession number GSE18951.

Three supplementary tables, showing the relationships in bacterial species between PFK (encoded by pfkA), the glucose-specific PTS transporter ElIB Glc (encoded by ptsG) and glucokinase, GK (encoded by $g / k$ ), are available with the online version of this paper. Additional data are also available with the online version of this paper in the form of the Excel file Additional data.xls, which includes six worksheets. The first worksheet, named 'model', contains the simplified metabolic model. The second worksheet, named 'abbreviations', contains a list of abbreviations of the metabolites. The third worksheet, named 'flux distributions', contains the calculated flux distributions of all experimental datasets. The fourth worksheet, named 'phylogenetic profiling', contains the phylogenetic profile of 373 species, and is available as a separate PDF. The fifth worksheet, named 'phylo reactions', contains the relevant reactions list and the amino acid sequences used for the phylogenetic profiling. The sixth worksheet, named 'transcriptome', contains the gene expression data. 


\section{INTRODUCTION}

The species Neisseria meningitidis (the meningococcus) is only found in humans, colonizing mucosal surfaces of the nasopharynx as a harmless commensal organism, and as such is carried by at least $5-10 \%$ of the adult population (Rosenstein et al., 2001; Stephens et al., 1983). Some strains are able to cross the mucosa into the bloodstream, from where they can cause the diseases meningitis and septicaemia. There are different pathogenic N. meningitidis isolates, of which five serogroups (A, B, C, Y and W135) are responsible for most disease. Conjugate polysaccharide vaccines that offer protection against infection with meningococcal serogroups A, C, Y and W-135 are effective and have been widely used (Girard et al., 2006; Trotter \& Ramsay, 2007). However, a broadly protective vaccine against infection by serogroup B $N$. meningitidis is not yet available, although this serogroup contributes significantly to the burden of meningococcal disease in many industrialized countries, where both epidemic and endemic serogroup B infections occur (Zimmer \& Stephens, 2006). At the Netherlands Vaccine Institute (NVI), a crossprotective multivalent vaccine against serogroup $\mathrm{B}$ organisms, including different subcapsular porin A (PorA) proteins contained in outer membrane vesicles (OMVs), is currently being developed. The vaccine development process focuses on cultivation of the organism, extraction of OMVs and subsequent purification of the PorA-containing OMVs (Baart et al., 2007b). Knowledge of the primary metabolism is essential for the development of a consistent cultivation step in the vaccine production process. For this reason, an $N$. meningitidis serogroup B genome-scale metabolic model has been built and used to study primary metabolism (Baart et al., 2007a, 2008). Earlier studies on glucose utilization in $N$. meningitidis confirm the presence of enzymes related to the glycolytic Embden-Meyerhof-Parnas (EMP) pathway, the Entner-Doudoroff (ED) pathway and the pentose phosphate (PP) pathway (Holten, 1974, 1975; Jyssum et al., 1961; Jyssum, 1962a, b, c) (Fig. 1). However, it has been found that the EMP pathway does not contribute to pyruvate synthesis, indicating that the EMP pathway is not functional. These observations are in accordance with the $N$. meningitidis serogroup B genome (Tettelin et al., 2000), in which a gene encoding phosphofructokinase (PFK) is not present. In order to improve the efficiency of the cultivation step in the vaccine production process we extended $N$. meningitidis metabolism with PFK. Furthermore, we used a comparative genomics approach to establish which factors determine the presence or absence of PFK in bacteria.

PFK (EC 2.7.1.11) is a key enzyme in glycolysis and is known to be regulated by allosteric effectors. The regulation of enzymes by allosteric effectors is a major mechanism of metabolic control, since it couples the activity of an enzyme to changes in the concentrations of metabolites produced by reactions that are distant in the metabolic network. PFK catalyses the irreversible phosphorylation of fructose 6phosphate (F6P) to fructose 1,6-bisphosphate (FBP) using ATP, and is allosterically inhibited by phosphoenolpyruvate
(PEP) and activated by ADP (or GDP) when the energy demand of the cell increases (Blangy et al., 1968). The ATPPFK described above (PFK-1) is broadly distributed in Eukaryota and Bacteria, as indicated by homologous protein sequences and biochemical evidence (Bapteste et al., 2003), and is encoded by the $p f k A$ gene. A second type of ATP-PFK enzyme (PFK-2), found strictly in Escherichia coli and encoded by the $p f k B$ gene, has a minor activity $(\sim 10 \%$ of the total) (Fraenkel, 1996) and is inhibited by ATP at low concentrations of F6P (Guixe \& Babul, 1985). The inorganic pyrophosphate $\left(\mathrm{PP}_{\mathrm{i}}\right)$-dependent $\mathrm{PFK}\left(\mathrm{PP}_{\mathrm{i}}-\mathrm{PFK}\right)$ catalyses the same reaction using $\mathrm{PP}_{\mathrm{i}}$ in a reversible manner, and can thus function in both glycolysis and gluconeogenesis. $\mathrm{PP}_{\mathrm{i}^{-}}$ PFK (EC 2.7.1.90) has a more limited distribution, but is also found in eukaryotes and bacteria (Bapteste et al., 2003). ATP-PFK and PP $_{\mathrm{i}}$-PFK share a common ancestry, but phylogenies show a very complex evolutionary pattern (Muller et al., 2001; Siebers et al., 1998). Some Archaea contain a unique ADP-dependent PFK (ADP-PFK) that appears to be phylogenetically distinct and instead belongs to the glucokinase family of kinases (Ito et al., 2001; Verhees et al., 2001). Bapteste et al. (2003) addressed the taxonomic distribution of ATP- and $\mathrm{PP}_{\mathrm{i}}$-dependent PFKs and concluded that numerous horizontal gene transfer (HGT) events and substitution of amino acids in the catalytic sites appear to occur at a high rate. None of the above-mentioned types of PFK are present in N. meningitidis. If it is assumed that $N$. meningitidis once had a functional PFK and that during the evolution of the species this activity was lost (Bapteste et al., 2003), the question of why N. meningitidis lost PFK activity remains. In particular, since glucose is present within nasopharyngeal tissue (Exley et al., 2005), the presence of PFK can yield one additional ATP per unit of substrate consumed, which is the case for all substrates that enter metabolism at a level above F6P.

It has been shown that Neisseria species preferentially take up DNA from their own genus (Davidsen \& Tonjum, 2006; Elkins et al., 1991), and this process of DNA exchange by HGT has been implicated in the evolution of $\operatorname{argF}$ (Zhou \& Spratt, 1992), alteration of penA resulting in penicillin resistance (Spratt et al., 1992), pilin antigenic variation (Seifert et al., 1988) and other genetic alterations. Since none of the Neisseria species of which the complete genome sequences are publicly available contain PFK homologues (Bentley et al., 2007; Parkhill et al., 2000; Peng et al., 2008; Tettelin et al., 2000; http://www.genome.ou.edu/gono_ new.html), HGT events within and between Neisseria species can never result in PFK functionality. However, DNA exchange between phylogenetically divergent species is possible (Omelchenko et al., 2003), as shown by the acquisition of sodC in $N$. meningitidis from Haemophilus influenzae by HGT (Kroll et al., 1998). Since H. influenzae contains a gene encoding $p f k A$, the possibility for $N$. meningitidis to obtain this gene exists. Hence, the question of why $N$. meningitidis did not acquire the $p f k A$ gene from, for instance, $H$. influenzae in order to enhance growth as in E. coli remains unanswered. In order to establish what 


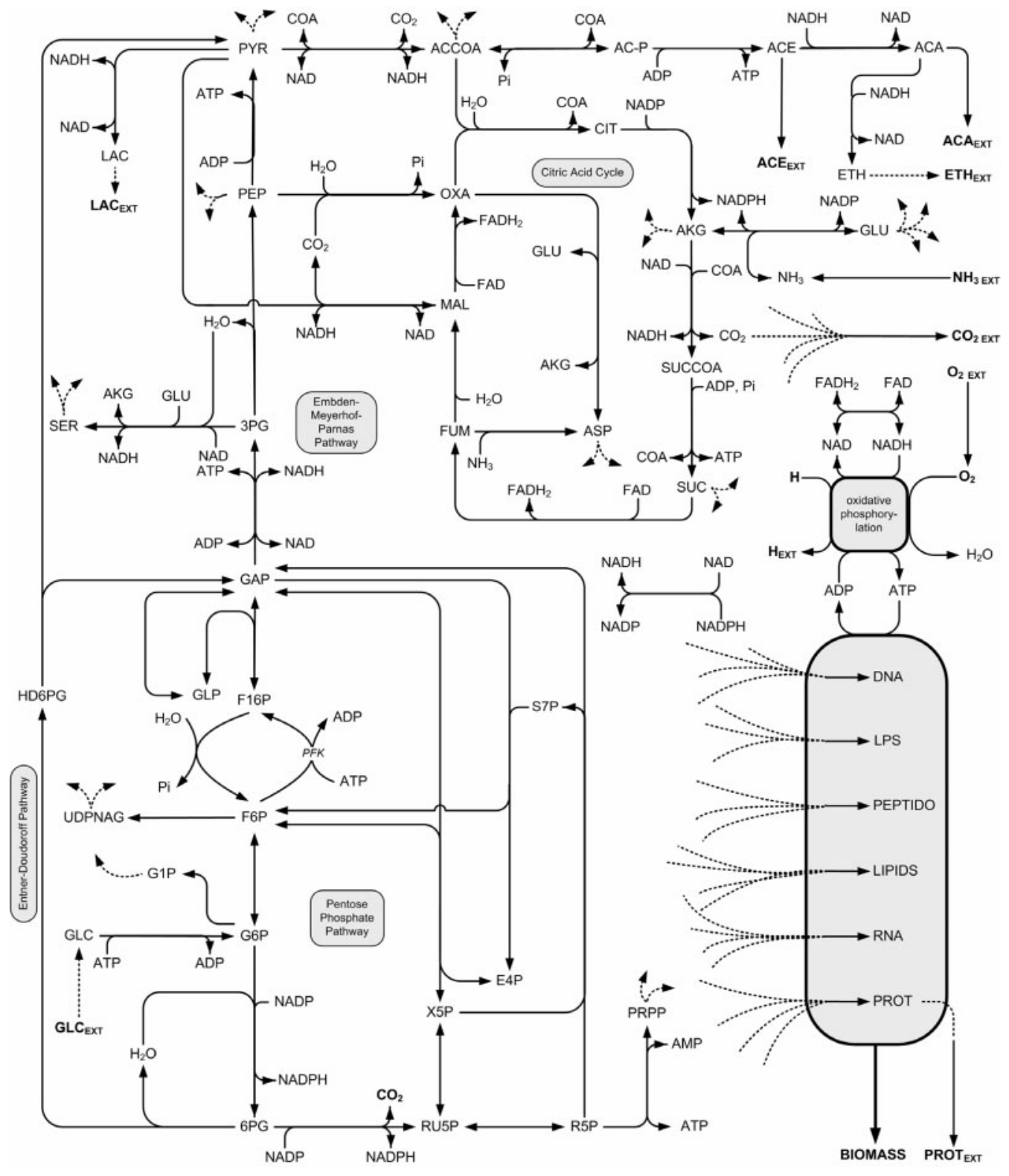

Fig. 1. Overview of N. meningitidis metabolism. The gene encoding PFK is not present in N. meningitidis. Abbreviations are listed in the abbreviations worksheet of the Additional Data spreadsheet available with the supplementary data.

determines the presence or absence of PFK in a species we used phylogenetic profiling and the literature as a starting point. In addition, we engineered a recombinant $N$. meningitidis strain to determine the influence of heterologous expression of PFK on biomass yield and composition, and analysed the strain at the metabolic and transcriptome level.

\section{METHODS}

Bacterial strains and growth conditions. Competent E. coli cells (strain TOP10, Invitrogen) were used for cloning purposes.
Transformants of E. coli were grown on solid or liquid LuriaBertani medium (BD Biosciences) containing either $100 \mu \mathrm{g}$ kanamycin $\mathrm{ml}^{-1}$ or $100 \mu \mathrm{g}$ ampicillin $\mathrm{ml}^{-1}$, and, when necessary, $1 \mathrm{mM}$ IPTG and X-Gal. N. meningitidis strain HB-1, a non-encapsulated, non-piliated variant of the group B isolate H44/76 (Bos \& Tommassen, 2005), was used for genetic modification. Untransformed N. meningitidis HB-1 cells were grown overnight on GC medium base plates (BD Biosciences) supplemented with IsoVitaleX (BD Biosciences) or in liquid meningococcal medium (van der Ley et al., 1993), while HB-1 derivatives were grown on GC medium base plates containing kanamycin $\left(100 \mu \mathrm{g} \mathrm{ml}^{-1}\right)$. All incubations were done in a $\mathrm{CO}_{2}$ incubator at $37^{\circ} \mathrm{C}$ in a humid atmosphere containing $5 \% \mathrm{CO}_{2}$. The final $N$. meningitidis $\mathrm{HB}-1$ mutants (HB- $1+k a n R$ and $\mathrm{HB}-1+k a n R+p f k A$ ) were used to generate bacterial stock cultures using chemically defined medium 
(Baart et al., 2007a) to ensure starting material of consistent quality for the chemostat cultures. After the addition of glycerol $(20 \%, \mathrm{v} / \mathrm{v}$, final concentration), the stock cultures were stored at $-135{ }^{\circ} \mathrm{C}$, and when required, a $500 \mathrm{ml}$ shake flask containing $150 \mathrm{ml}$ medium was inoculated with $10 \mathrm{ml}$ stock culture that contained $0.5 \mathrm{~g}$ biomass $\mathrm{l}^{-1}$. After approximately $8 \mathrm{~h}$ of incubation at $35^{\circ} \mathrm{C}$ with shaking at 200 r.p.m. in an aerobic humid atmosphere, the culture was used to inoculate the bioreactor. Bacteria were grown on minimal chemically defined medium (Baart et al., 2007a) in 31 autoclavable ADI bioreactors (Applikon), operated in chemostat mode, with a working volume of $1.4 \mathrm{l}$. Temperature, $\mathrm{pH}$, dissolved oxygen (DO) concentration and stirrer speed were $37{ }^{\circ} \mathrm{C}, 7.0,30 \%$ and 600 r.p.m., respectively. The total gas flow rate was kept constant at $1.01 \mathrm{~min}^{-1}$. The oxygen concentration was controlled by changing the oxygen fraction in the gas flow using headspace aeration only. The growth rate was $0.13 \mathrm{~h}^{-1}$. After at least four residence times, physiological steady state was assumed based on online measurements (constant DO signal, $\mathrm{O}_{2}$ and $\mathrm{CO}_{2}$ concentration in the off-gas) and offline measurements (constant optical density, glucose concentration). In steady state, four small samples were taken using a rapid sampling procedure as described below, and a large 1.01 sample was taken, divided into portions and processed as described previously (Baart et al., 2007a). All chemostats were run in duplicate.

Analytical procedures. Dry biomass concentration was determined by fourfold measurements for each steady-state sample by centrifugation $(8000 \mathrm{~g})$ of $50-200 \mathrm{ml}$ culture broth in preweighed tubes followed by drying $\left(24 \mathrm{~h}, 80^{\circ} \mathrm{C}\right)$. Before weighing, the tubes were cooled in a desiccator for at least $1 \mathrm{~h}$ and dry cell weight $(\mathrm{dcw})$ was corrected for salts present in the medium. The $\mathrm{O}_{2}$ and $\mathrm{CO}_{2}$ concentrations in the exhaust gas from the chemostat cultures were measured with a mass spectrometer (Prima White Box 600, Thermo Electron). The volumetric oxygen transfer coefficient, $\mathrm{k}_{\mathrm{L}} \mathrm{a}$, in the bioreactors was determined accurately at $37{ }^{\circ} \mathrm{C}$ using a steady-state set-up similar to that used by Dorresteijn et al. (1994). Glucose, lactate and ammonium in the culture supernatant were determined as described previously (Baart et al., 2007a). Acetate, ethanol and other possible metabolites present in the culture supernatant were determined by ${ }^{1} \mathrm{H}-\mathrm{NMR}$ as described previously (Baart et al., 2007a). The molecular and macromolecular composition of biomass was determined experimentally as described previously (Baart et al., 2007a, 2008), and was very important in mathematical modelling of cellular metabolism (Lange \& Heijnen, 2001). PFK activity was measured enzymically in cell-free extracts using a coupling enzyme assay (Fordyce et al., 1982). Briefly, cell-free extract was obtained by applying five freeze/thaw cycles to the cells, which were resuspended in MilliQ water, followed by centrifugation $(8000 \mathrm{~g}, 30 \mathrm{~min})$, to remove insoluble cellular fragments, and sterilization of the lysate by filtration $(0.22 \mu \mathrm{m}$ pore-size). To determine PFK activity, $50 \mu \mathrm{l}$ cellfree extract was added to $900 \mu \mathrm{l}$ of a $55.56 \mathrm{mM}$ Tris/HCl buffer ( $\mathrm{pH} 7.5$ ) containing $5.56 \mathrm{mM} \mathrm{MgCl}_{2}, 55.56 \mathrm{mM} \mathrm{KCl}, 1.39 \mathrm{mM}$ ATP, $0.17 \mathrm{mM} \mathrm{NADH}, 1.8 \mathrm{U}$ aldolase $\mathrm{ml}^{-1}, 8.89 \mathrm{U}$ triose phosphate isomerase $\mathrm{ml}^{-1}$ and $2.27 \mathrm{U}$ glycerol phosphate dehydrogenase $\mathrm{ml}^{-1}$. The reaction was started by adding $50 \mu \mathrm{l}$ F6P solution $(100 \mathrm{mM})$. PFK activity was determined by measuring the decrease in $A_{340}$ (as a consequence of NADH oxidation) for $10 \mathrm{~min}$. E. coli cell-free extract was used as a positive control for PFK activity, whereas cell-free extract of $N$. meningitidis HB- $1+k a n R$ was used as a negative control (and blank).

Recombinant DNA techniques. Since E. coli plasmids are not able to persist in $N$. meningitidis, and because no high-copy-number plasmids exist for $N$. meningitidis, heterologous expression of a gene can only be achieved by homologous recombination. To use this strategy, the gene of interest has to be inserted into a vector between DNA sequences homologous to the site at which the gene has to be inserted into the genome. Besides being used for homologous recombination, these homologous sequences must also contain a DNA uptake sequence. A kanamycin resistance gene must be present between the homologous regions to select for transformants after transformation. The final plasmid constructed in this study that was used for transformation of $N$. meningitidis strain HB-1 contained a sequence homologous to a DNA sequence situated just downstream of the rmpM gene, which encodes a class 4 outer-membrane protein. This is the location of choice, because of constitutive expression of genes from this site (van der Ley \& van Alphen, 2001). Incorporation of heterologous $p f k A$ at this site leads to its expression by the $r m p M$ promoter. Although standard methods were used for DNA preparation, restriction enzyme analysis, cloning and sequencing (Sambrook et al., 1989), the cloning procedure to obtain the $p f k A+$ phenotype $(\mathrm{HB}-1+k a n R+p f k A)$ and the HB- $1+k a n R$ control phenotype is described briefly below.

PCR and sequencing. After identification of the location of the $p f k A$ gene in E. coli K-12 using the NCBI database, PCR was used to amplify an E. coli DNA fragment containing $p f k A$ with Taq polymerase. Sci Ed Clone Manager 6 (Scientific \& Educational Software) was used to design the forward (5'-CAAGAAGACTTCCGGCAACA- $\left.3^{\prime}\right)$ and reverse oligonucleotide primers $\left(5^{\prime}\right.$ TGATAAGCGAAGCGCATCAG-3'). Primers were synthesized by Sigma-Genosys. The forward primer anneals $55 \mathrm{bp}$ upstream of the ATG start codon while the reverse primer anneals 79 bp downstream of the TAA stop codon, which results in a $p f k A$-containing DNA fragment of $1096 \mathrm{bp}$.

The primers were diluted to a concentration of $1 \mu \mathrm{mol} \mathrm{ml}^{-1}$ and were added to puReTag ready-to-go PCR beads (Amersham Biosciences) prior to the addition of $E$. coli cells. Using six combinations of mixtures containing various amounts of primers and E. coli cells, PCR was carried out (GeneAmp PCR system 9600, Perkin Elmer) using the following cycling conditions. Initial denaturation of the template DNA at $94{ }^{\circ} \mathrm{C}$ for $5 \mathrm{~min}$ followed by 30 cycles of $94{ }^{\circ} \mathrm{C}$ for $15 \mathrm{~min}$, $55^{\circ} \mathrm{C}$ for $30 \mathrm{~s}$ and $72{ }^{\circ} \mathrm{C}$ for $1 \mathrm{~min}$, and completed with $7 \mathrm{~min}$ at $72{ }^{\circ} \mathrm{C}$ and $4{ }^{\circ} \mathrm{C}$ until further processing. From each reaction mixture, $10 \mu \mathrm{l}$ was added to $4 \mu \mathrm{l}$ loading buffer ( $1 \mathrm{mM}$ EDTA, $0.25 \%$ bromophenol blue, $40 \%$ sucrose) and analysed on a $1 \%$ agarose gel using $1 \times$ TBE buffer (Bio-Rad) at $100 \mathrm{~V}$ for $30 \mathrm{~min}$, to check for sufficient amplification of the DNA fragment. It was found that $10 \mu \mathrm{l}$ primers in combination with $1-2 \mu \mathrm{l} E$. coli cells gave the best results (results not shown). The generated $1096 \mathrm{bp}$ fragment was cloned into the pCR 2.1-TOPO plasmid, using the TOPO TA cloning kit (Invitrogen), according to the manufacturer's protocol. The plasmids were purified from the culture using a miniprep kit (Promega). After digestion of the plasmid DNA $\left(37^{\circ} \mathrm{C}, 2 \mathrm{~h}\right)$ using HindIII and EcoRV, samples were analysed for the presence of the $p f k A$ gene by agarose gel electrophoresis, and fragments were purified from the gel using the Promega Gel and PCR Clean-Up system according to the manufacturer's protocol. Fragments were checked by sequencing using the ABI Prism DNA sequencing kit (Applied Biosystems) according to the manufacturer's protocol. In order to obtain reliable sequencing results, a primer annealing at position 359 of the DNA fragment was designed (5'-GGCGGTGACGGTTCCTACAT- $\left.3^{\prime}\right)$ and sequencing was performed on an ABI Prism 310 genetic analyser (Applied Biosystems). Sequencing of eight pCR-TOPO-pfkA constructs resulted in one usable construct (pTOPO-pfkA).

Constructs. A pCF-linker plasmid, containing the sites necessary for DNA uptake and homologous recombination was available from previous studies (van der Ley et al., 1995). Since a usable construct has to contain a kanamycin resistance gene $(k a n R)$ next to the $p f k A$ gene and both genes have to be cloned in the BamHI site of the pCFlinker plasmid, a construct was prepared containing both the kanamycin resistance gene and $p f k A$. Briefly, the procedure was as follows. First, the pTOPO-pfkA plasmid and a pBluescript vector, 
which contains an ampicillin resistance gene (Stratagene), were digested by HindIII and EcoRV. Digestion of the pTOPO-pfkA by these enzymes resulted in an $1173 \mathrm{bp}$ fragment containing $p f k A$ which was purified as described above. Second, the purified fragment was ligated into the pBluescript vector (pBlue- $p f k A$ ) and transformation was done in medium containing ampicillin. Third, a kanamycin resistance gene was obtained from an available pUC4K vector (van der Ley et al., 1995) by digestion with PstI and subsequent purification. The kanamycin resistance gene was ligated into the pBlue- $p f k A$ vector ( $p B l u e-P K$ ) and transformant selection was done in medium containing kanamycin. After purification of the resulting plasmid DNA, the orientation of the kanamycin resistance gene was checked by XhoI digestion. Plasmids containing the correct orientation were selected, yielding the required $p f k A-k a n R$ fragment. After ligation of the $p f k A-k a n R$ fragment into the BamHI site of pCFlinker, transformation of competent E. coli cells was carried out and transformant selection was done in medium containing kanamycin, yielding the final pCF-linker-pfkA-kanR plasmid (pCF-PK). For correct expression by the rmpM promoter, the orientation of the fragment was checked by $\mathrm{NdeI}$ and $\mathrm{XbaI}$ digestion. Plasmids containing the fragment in the correct orientation were selected and used for transformation of $N$. meningitidis HB-1. After transformation, a PCR was done with the primers for $p f k A$, which confirmed the presence of the inserted DNA fragment. The control strain was created by cutting both pCF-linker and pUC4K with $B a m H I$. After purification of the fragments, $k a n R$ was ligated into pCF-linker, yielding the pCF-K plasmid. The orientation of kanR in this construct was checked by digestion with $\mathrm{Xba \textrm {I }}$ and ClaI. This construct was used for transformation of N. meningitidis HB-1.

Transformation. The plasmid-constructs (pCF-PK and pCF-K) were cut using KpnI and the linear DNA was used for transformation. Overnight-grown $N$. meningitidis strain HB-1 was scraped from the gonococcal (GC) agar plate using a swab and resuspended in $10 \mathrm{ml}$ meningococcal medium containing $10 \mathrm{mM} \mathrm{MgCl}_{2}$. The suspension was diluted fivefold in the same medium. A $2.5 \mu \mathrm{l}$ volume of linear construct DNA $\left(1 \mu \mathrm{g} \mathrm{ml}{ }^{-1}\right)$ was added to $2.5 \mathrm{ml}$ of the diluted suspension. After transformation $\left(37^{\circ} \mathrm{C}, 3 \mathrm{~h}\right), 250 \mu \mathrm{l}$ suspension was plated on GC agar plates containing kanamycin. Plates were stored overnight in $\mathrm{a} \mathrm{CO}_{2}$ incubator. Colonies obtained this way were picked and plated again on kanamycin-containing GC plates to get rid of untransformed cells, which remain alive but cannot grow in the presence of kanamycin. This procedure was repeated once to obtain a total of three plating steps on kanamycin-containing medium. The final $N$. meningitidis HB-1 mutants (HB-1+kanR and HB$1+k a n R+p f k A)$ were used to generate stock-cultures.

Rapid sampling. When the chemostat cultures were run, a fullgenome N. meningitidis microarray was not yet available at the NVI. For this reason we decided to quench the culture broth using a rapid sampling procedure followed by low-temperature storage to freeze bacterial metabolism and preserve RNA. The practical rapid sampling setup of Lange et al. (2001) was adjusted by addition of air filters $(0.2 \mu \mathrm{m}$ pore-size $)$ at the relevant points to construct a closed system that was suitable for working with pathogens. In steady state, four samples of $5 \mathrm{ml}$ were taken in $35 \mathrm{ml}-40{ }^{\circ} \mathrm{C}$ quenching solution [60\% (w/w) methanol buffered with $10 \mathrm{mM}$ HEPES, pH 7.5 (Lange et al., 2001)] and stored at $-80{ }^{\circ} \mathrm{C}$ until further analysis. The quenched samples were stored for 2 years prior to RNA isolation.

Microarrays. Samples were analysed using a full-genome $N$. meningitidis microarray. Based on the genome sequence of $N$. meningitidis serogroup B strain MC58 (Tettelin et al., 2000), a set of 2078 70-mer oligonucleotides was developed at Operon (Germany), covering $93 \%$ of all predicted ORFs. In addition, a single 70-mer $p f k A$ oligonucleotide sequence from E. coli $\mathrm{K}-12$ was added to the set. Oligonucleotide pellets were dissolved in $50 \%$
DMSO (v/v, in water) to a concentration of $20 \mu \mathrm{M}$ and spotted in triplicate on UltraGAPS II coated slides (Corning), using the Omnigrid 100 microarray spotter (GeneMachines). During steady state, duplicate RNA samples were taken from one chemostat for each bacterial strain. The third RNA sample was taken from the duplicate chemostats, giving a total of four chemostat cultivations. For each microarray sample, the quenched bacterial culture samples were used directly for RNA isolation. The amount of quenched bacterial culture used for RNA isolation was equal to $1.2 \mathrm{ml}$ per $\mathrm{OD}_{590}$ unit to ensure that an equal amount of bacteria was used as starting material. The samples were concentrated by centrifugation $(3000 \mathrm{~g}, 15 \mathrm{~min})$ and treated with Tris-EDTA buffer containing $0.5 \mathrm{mg}$ lysozyme $\mathrm{ml}^{-1}$ (Sigma-Aldrich) for $3 \mathrm{~min}$. Total RNA was extracted with the SV Total RNA isolation system according to the manufacturer's protocol (Promega Benelux). Nucleic acid concentration was adjusted by precipitation and spectral analysis was used to determine final nucleic acid concentration and purity. RNA integrity was confirmed with the Bioanalyser RNA6000 Nano assay (Agilent Technologies), according to the manufacturers' protocol. RNA integrity was predicted by calculation of the RNA integrity number (RIN) (Schroeder et al., 2006).

Total RNA from three experimental samples per strain was reversetranscribed to cDNA and labelled with Cy3 dye using the Chipshot Indirect Labeling and Clean-Up kit (Promega Benelux) according to the manufacturer's protocol, with one deviation: $2 \mu \mathrm{l}$ random primer and no oligo-dT primer was used per reaction to reverse transcribe the RNA. Common reference samples, containing equal amounts of total RNA from all three experimental samples, were labelled with Cy5. The labelled and purified cDNA samples were pooled in $\mathrm{Cy} 3 /$ Cy5 pairs and volumes were adjusted to $25 \mu \mathrm{l}$. An equal volume of hybridization buffer was added, to a final concentration of $25 \%$ formamide, $5 \times$ SSC and $0.1 \%$ SDS. Samples were applied to the microarray slides and placed in a hybridization chamber (GeneMachines) for $16-20 \mathrm{~h}$ at $42{ }^{\circ} \mathrm{C}$ in the dark. Differential gene expression levels were calculated through comparison with a common reference sample, containing equal amounts of RNA from all experimental samples. The microarrays were scanned with a ScanArray Express microarray scanner (Perkin Elmer) and median fluorescence intensities were quantified for each spot using ArrayVision software (Imaging Research). The expression data were natural-log-transformed and quantile-normalized, and values of replicate spots were averaged. These data processing steps were done with the free statistical software R (WU), using an in-housedeveloped script. $P$ values were calculated using one-way ANOVA statistical analysis. Fold ratio (FR) values were expressed as the natural $\log$ of the normalized signal difference between the two groups. A $P$ value below 0.05 was used to select differentially expressed genes. To further select for biologically relevant effects, only genes that combined both a low $P$ value with and an FR above 2.00 were included in the final results (see Supplementary Material, transcriptome worksheet).

Phylogenetic profiling. To determine the presence or absence of the $p f k A$ gene and other genes related to glucose metabolism and glucose transport, in different species, the STRING database (http:// string.embl.de/; von Mering et al., 2005) was used as a starting point. The protein sequences of the relevant genes of E. coli were used as an input. In cases where no or very low homology was found in $N$. meningitidis, although functionality has been indicated elsewhere (http://www.biocyc.org/; http://www.genome.ad.jp/kegg/), the protein sequences of the relevant genes of $N$. meningitidis were also used as input. In order to interpret the results obtained from the alignments more easily, the STRING scores were converted to a colour scale based on four colours using an in-house computer program running in Visual Basic (Microsoft). In this program the homology scores (bitscores) of the relevant protein sequence of a 
species serve as an input. In the cases where no sequence homology was found, the colour red was assigned. In the cases where some homology was found but the bitscore was below the general threshold value of 60 (http://string.embl.de/), the colour orange was assigned. The genes that were present are indicated by the colour green and high homology (high scores) are indicated by a slightly darker green. The reliability of the colour rescaling was checked by crossreferencing using BLASTP and two randomly chosen protein sequences, which confirmed the results obtained.

Metabolic modelling. Methods for solving a metabolic network or set of linear equations have been discussed extensively elsewhere (Edwards et al., 1999, 2001; Forster et al., 2002; Vallino \& Stephanopoulos, 1990; van Gulik \& Heijnen, 1995). Briefly, first the genome-scale metabolic model (Baart et al., 2007a) was simplified as described previously (Baart et al., 2008). Next, an acetaldehyde exchange reaction was added based on the measurement of acetaldehyde in the culture supernatant. In addition, for the HB$1+k a n R+p f k A$ strain, the irreversible PFK reaction was added to the model (see Supplementary material, model worksheet). For both cases, the primary measurements were translated to measured conversion rates using mass balances, and all measurement errors were translated to errors (i.e. variances) in measured conversion rates using Monte Carlo simulation (MCS), as described previously (Baart et al., 2007a).

The redundancy matrix expressing the redundancy relations between the measured exchange rates was calculated for each individual dataset and contained two independent equations. Inspection of these equations indicated a carbon and a nitrogen balance. Both metabolic models (HB- $1+k a n R$ and $\mathrm{HB}-1+k a n R+p f k A)$ are partly underdetermined. Linear optimization (i.e. linear programming, LP) was combined with MCS and used to find a single, unique, optimal value for the objective function maximization of ATP hydrolysis as described previously (Baart et al., 2008). Since ATP is an intermediate metabolite that cannot accumulate, maximization of the hydrolysis reaction automatically means that in the rest of the network ATP production is maximized. It is noteworthy that this single solution is not necessarily unique and that there can be more than one flux distribution that reaches the optimal value of the objective function.

In silico flux balance analysis (FBA). Prior to balancing and LP (FBA), in silico FBA simulations were done in order to determine the possible increase in yield as a result of the introduction of $p f k A$. The protein, fatty acid and biomass biosynthesis reactions in the in silico FBA simulations were based on the measured average composition which had been determined previously (Baart et al., 2008). The following external metabolites were allowed to freely enter and leave the system: ammonia, water, phosphate, thiosulfate, sulfate, carbon dioxide, oxygen and protons. In addition, amino acids, acetate, hydrogen sulfide, ethanol and extracellular protein were only allowed to leave the system. Glucose was the sole carbon source that was allowed to enter the system. The objective function used in in silico FBA was the maximization of biomass. This objective function was found to result in biologically meaningful predictions in nutrientlimited continuous E. coli cultures (Schuetz et al., 2007). In silico FBA was combined with MCS using previously determined substrate $\left(\mathrm{Y}_{\mathrm{x} / \mathrm{s}}\right.$, $\left.\mathrm{m}_{\mathrm{s}}\right)$ and energy parameters $\left(\mathrm{Y}_{\mathrm{x} / \mathrm{ATP}}, \mathrm{m}_{\mathrm{ATP}}\right)$ and their corresponding variances (Baart et al., 2008) as input for optimization at different chosen growth rates. The complete procedure was as follows. First, a growth rate was chosen and at this growth rate a thousand values for the corresponding consumption rate of glucose, the growthassociated ATP requirement for biomass and the flux through the non-growth-associated ATP-maintenance reaction $\left(\mathrm{m}_{\mathrm{ATP}}\right)$ were calculated using MCS and stored as temporary dataset. Second, each set of these simulated values was used as input for in silico FBA and the flux distribution results were stored in a second temporary matrix.
After completion of the simulations at the chosen growth rate, the mean value and the corresponding variance of each flux and exchange rate were calculated. Then the next growth rate was selected and the above described procedure was done again. After completion of the in silico FBA calculations for strain $\mathrm{HB}-1+k a n R$, the stoichiometric matrix corresponding to strain $\mathrm{HB}-1+k a n R+p f k A$ was selected and the complete procedure was repeated using the same growth rates as an input. The Monte Carlo approach was used in order to estimate the errors in the calculated in silico yield values $\left(\mathrm{Y}_{\mathrm{x} / \mathrm{s}}^{\text {insilico }}\right)$ at the different growth rates in the two strains. The stoichiometric matrices used in this study were constructed from the set of reactions using a custom made computer program running in Visual Basic (Microsoft). Both MCS and FBA were executed in custom-made computer programs running in Matlab (version 6.5 r13; Mathworks).

\section{RESULTS AND DISCUSSION}

\section{In silico FBA}

A functional glycolysis in $N$. meningitidis by inclusion of PFK theoretically leads to an increase in the biomass yield, as shown in Fig. 2. The possible increase in biomass yield is higher when the growth rate is lower, as expected. Since functional glycolysis only produces one additional ATP molecule to add to a total of about 20 ATPs in central metabolism, the effect of PFK when cells grow at a low growth rate becomes relatively more important, since the availability of ATP for biomass growth decreases with decreasing growth rates due to maintenance requirements. In other words, the more limiting energy becomes for growth the more important it is to increase the yield of

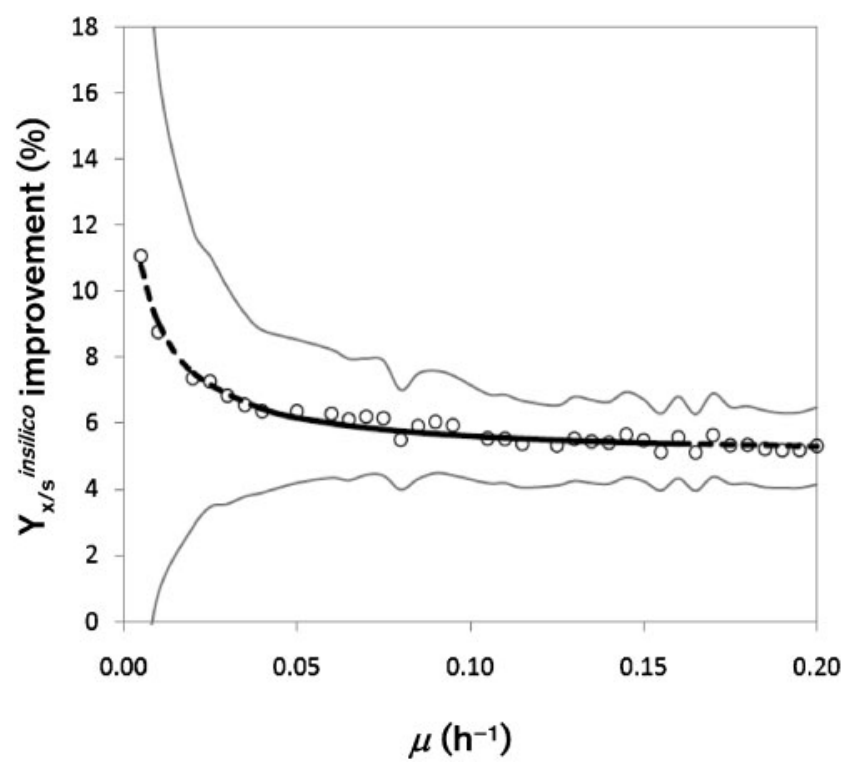

Fig. 2. Percentage improvement of in silico biomass yield $\left(\mathrm{Y}_{\mathrm{x} / \mathrm{s}}^{\text {insilico }}\right)$ in the $p f k A^{+}$strain at various growth rates $(\mu)$ in comparison with the HB-1+kanR strain. The grey lines represent the SD of the predictions $(\bigcirc)$. Since the substrate and energy parameters (see Methods) were estimated in the $0.04-0.16$ range of growth rates, the mean line (black) is dashed outside this range. 
ATP on a substrate and thus the more advantageous PFK becomes.

\section{Phylogenetic profiling}

Phylogenetic profiling (see Supplementary Material, phylogenetic profiling worksheet) reveals that many genomes of both $\gamma$ - and $\delta$-Proteobacteria, Acidobacteria, Firmicutes, Bacteroidetes, Actinobacteria, some Cyanobacteria and all Eukaryota contain a $p f k A$ gene (or a $p f k A$ homologue), while it is absent in most $\alpha$-Proteobacteria, $\beta$-Proteobacteria and Chlamydiae genomes, and in Archaea (see Supplementary Material). Notably, all listed Firmicutes, $\delta$-Proteobacteria and Acidobacteria contain a $p f k A$ homologue. The presence of $p f k A$ in all listed families, but not in Archaea, indicates that its origin is ancient. However, its phylogenetic distribution is patchy and complex. For instance, the genomes of two species within the listed $\beta$-Proteobacteria (i.e. Rhodoferax ferrireducens and Chromobacterium violaceum) contain a $p f k A$ homologue, while all other species do not. Observations within all the described families of Bacteria show similar results. In other words, there always seem to be one or more species within a family that contains a $p f k A$ gene, so phylogenetically based discrimination to reconstruct the evolutionary history of $p f k A$ does not seem possible. However, the patchy phylogenetic distribution suggests, as indicated elsewhere (Bapteste et al., 2003), that $p f k A$ can be lost during the evolution of a species. Phylogenetic profiling indicates that the genomes of most anaerobic organisms (e.g. Clostridium species) contain a $p f k A$ gene. Since little energy is generated from substrate in anaerobically grown species, the relative gain in ATP yield increases significantly when the glycolytic pathway is present. This is in agreement with the obtained in silico FBA results, since at a low growth rate, an increased yield is predicted. The absence of a $p f k A$ gene in anaerobic organisms goes together with the absence of genes related to the EMP pathway and/or the absence of glucose transport capabilities. In facultative anaerobic species, the presence or absence of a $p f k A$ gene is more variable. For instance, the genomes of Escherichia species, Shigella species, Salmonella species, Haemophilus species, Mannheimia succiniciproducens, Staphylococcus species, Corynebacterium species, Listeria species, Yersinia species and Vibrio species contain a $p f k A$ homologue, while the genomes of Legionella species, Chlamydophila species and Chlamydia species do not. In the genomes of the last three genera, additional genes related to the EMP pathway are also not present. Similar to facultative anaerobic species, the distribution of the $p f k A$ gene in obligate aerobic species is variable; however, most obligate aerobic species seem to lack $p f k A$ (e.g. Burkholderia, Neisseria, Helicobacter and Bordetella species). From an energy point of view, the lack of $p f k A$ in an obligate aerobe seems obvious, since the contribution of PFK to the energy supply in an aerobically grown organism is limited in comparison with the energy generated through oxidative phosphorylation, which might explain the absence of $p f k A$ in the N. meningitidis genome. In other words, under aerobic conditions, the substrate is more important for anabolism (i.e. supply of intermediates for growth), than for generating energy. Under anaerobic or microaerobic conditions the reverse is true; the substrate is more important for energy generation than for anabolism, and PFK provides an advantage. Therefore, in the case of a limiting energy supply, the objective of an organism seems to be to optimize the yield of energy from a substrate (maximize $Y_{\mathrm{ATP} / \mathrm{s}}$ ). In contrast, in the case of sufficient available energy, it seems that the strategy of organisms is to consume this energy as fast as possible (maximize $\mathrm{r}_{\mathrm{ATP}}$ ) in order to outcompete other micro-organisms living in the same habitat. However, there always seems to be a trade-off between high biomass yield and the high energy dissipation rates necessary for fast growth, as examined extensively by von Stockar and coworkers (Liu et al., 2007; von Stockar et al., 2006). Schuetz et al. (2007) found that under carbon (and energy) limitation in a chemostat, E. coli aims at maximization of biomass. In the case of an excess availability of carbon (and energy), the E. coli metabolism operates in such a way that a minimal number of biochemical reactions are used to generate the required ATP. This typical overflow metabolism (e.g. production of acetate) results in less efficient energy utilization of the carbon source. Nevertheless, the resulting suboptimal yields go hand in hand with dissipation of more energy and thereby enable higher catabolic rates (Schuetz et al., 2007), which might be a way to outcompete other organisms living in the same habitat. Furthermore, the excreted products such as acetate and ethanol may inhibit the growth of other organisms. This shows that E. coli has developed a mechanism that compromises between growth efficiency (i.e. biomass yield) and metabolic rate (i.e. growth rate), and the environmental conditions (i.e. habitat) determine which mechanism is preferred. There is more experimental evidence showing that at carbon substrate limitation, high-yield pathways are indeed adopted (Brauer et al., 2005; Postma et al., 1989; Vulic \& Kolter, 2001).

In N. meningitidis, glucose uptake proceeds via glucokinase (NMB1390). In the genomes of Staphylococcus and Streptococcus, other known inhabitants of the nose and throat, $p f k A$ is present while glucokinase is absent, and glucose uptake proceeds via the PEP : carbohydrate phosphotransferase system (PTS system). PTS-mediated substrate uptake involves the transfer of the phosphoryl group of the high-energy metabolite PEP to the carbohydrate through a cascade of phosphotransfer proteins (Deutscher et al., 2006; Postma et al., 1993). The significantly decreasing transcription level of $p f k A$ in a PTS-deficient E. coli mutant ( $\Delta$ ptsHIcrr) in comparison with the wildtype (Flores et al., 2005) suggests that there is a correlation between PFK and PTS. Since a functional EMP pathway can generate twice as much PEP from glucose than the ED pathway, the presence of PFK and the PTS system indeed seems to go hand in hand. To illustrate the possible correlation between PFK and the PTS system, Fig. 3 shows Venn diagrams for $p f k A, g l k$ (glucokinase, GK) and $p t s G$ (glucose-specific PTS transporter $\mathrm{EIIB}^{\mathrm{Glc}}$ ) in $\gamma$ - and $\beta$ - 


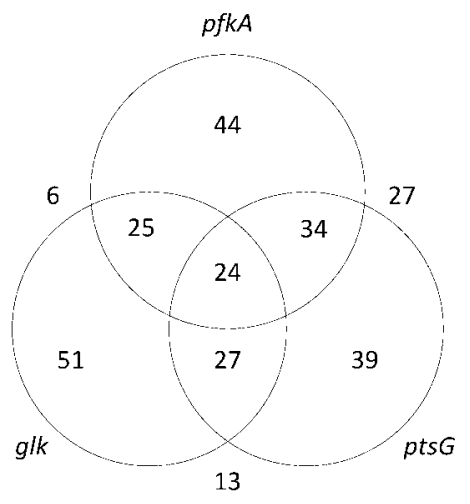

$\gamma$-proteobacteria (76/4)

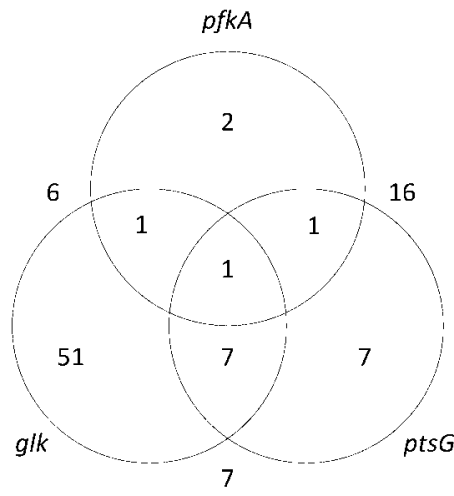

$\beta$-proteobacteria $(24 / 6)$

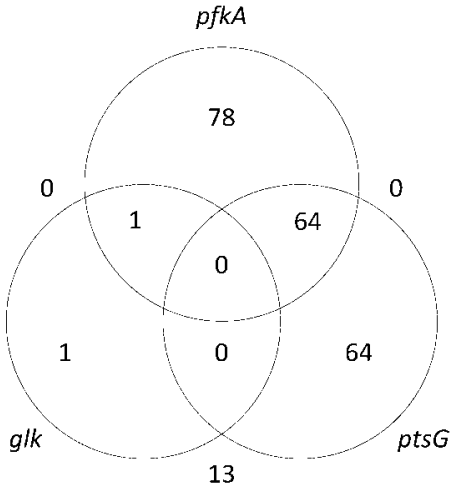

Firmicutes (78/0)

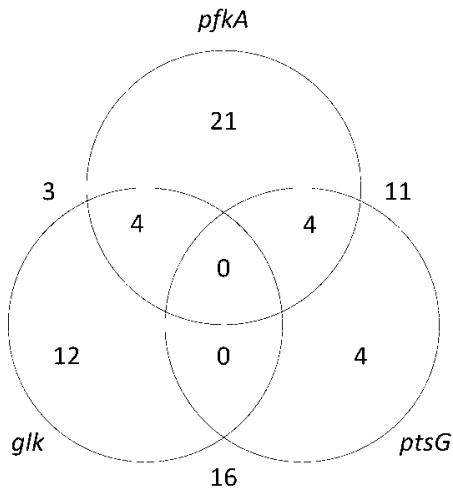

Actinobacteria (32/3)
Fig. 3. Venn diagrams indicating the relationship (numbers in the circles) between PFK (encoded by $p f k A$ ), the glucose-specific PTS transporter ElIB ${ }^{\mathrm{Glc}}$ (encoded by ptsG) and glucokinase (GK; encoded by $g / k$ ) in $\gamma$ Proteobacteria, $\beta$-Proteobacteria, Firmicutes and Actinobacteria. For example, in 76 of the listed $\gamma$-Proteobacteria, pfkA, ptsG and $g l k$ homologues are present in 44, 39 and 51 species, respectively. In 34 species, $p f k A$ and pts $G$ homologues are both present, whereas in 27 species, pfkA and pts $G$ homologues are both absent (number outside the circles). Hence, in $61(27+34)$ of the 76 cases (80\%), PFK and EllB ${ }^{\mathrm{Glc}}$ are correlated. In 25 species, $p f k A$ and $g l k$ homologues are both present, whereas in six species, $p f k A$ and $g l k$ homologues are both absent. Therefore, in 31 cases (41\%), PFK and GK are correlated. In 27 species, glk and pts $G$ homologues are both present, whereas in 13 organisms, glk and pts $G$ homologues are both absent (correlation in $53 \%$ of the cases). In 24 of the $76 \gamma$ Proteobacteria (number in the centre), all three homologues are present, whereas homologues are absent in four cases (4/76), which means that in $37 \%$ of the cases, PFK, EllB ${ }^{\mathrm{Glc}}$ and GK are correlated.
Proteobacteria, Firmicutes and Actinobacteria. No pts $G$ homologs have been found in $\varepsilon^{-}$and $\delta$-Proteobacteria, Acidobacteria, Chlamydiae, Bacteroidetes and Cyanobacteria species, whereas $p f k A$ homologues are present in some of these species (see Supplementary Tables S1-S3). From the Venn diagrams (Fig. 3) it can be calculated that in 157 of the 210 cases, PFK and EIIB ${ }^{\text {Glc }}$ are correlated (75\%), meaning that either they are found together or neither is present, or, stated differently, in the 156 cases where either PFK or $\mathrm{EIIB}^{\mathrm{Glc}}$ is present, they are present together in 103 cases, which indicates that they are correlated. PFK and GK are correlated in $22 \%$ of the cases, and GK and $\mathrm{EIIB}^{\mathrm{Glc}}$ are correlated in $40 \%$ of the cases. In 38 of the 210 cases shown in the Venn diagrams (18\%), PFK, EIIB ${ }^{\mathrm{Glc}}$ and GK are correlated. When the 312 bacterial species listed in the phylogenetic profile are taken into consideration, PFK and EIIB $^{\text {Glc }}$ are correlated in $69 \%$ of the cases (see Supplementary Tables S1-S3). Notably, phylogenetic profiling indicates that the EI PTS protein (encoded by $p t s I$ ), is present in 92, 20 and $96 \%$ of the Bacteria, Eukaryota and Archaea, respectively, which clearly indicates more (ancient) functional roles for the PTS system.

Since the PTS system is typical for anaerobic and facultative aerobic organisms (Postma et al., 1993), the lack of a PTS system in N. meningitidis seems obvious.
Although, during infection, pathogenic N. meningitidis encounters host anatomical sites with low oxygen levels, which indicates that anaerobic metabolism is required (Bartolini et al., 2006; Nassif et al., 1999), one can argue that this requirement is not a main determinant of $N$. meningitidis evolution; in particular, natural evolution of $N$. meningitidis takes place in the aerobic nasopharyngeal mucosa. The possibility cannot be ignored that other main nutrients for growth (for example lactate), which are not processed via F6P and are present the natural habitat of $N$. meningitidis, might also be determinants of $p f k A$ deficiency in N. meningitidis. In conclusion, for growth on hexose sugars, whether a micro-organism is strictly anaerobic or strictly aerobic seems to be the most important factor determining the presence or absence of PFK, and is correlated with the presence or absence of a PTS system, respectively, and thus can also explain the absence of PFK in N. meningitidis, which is an aerobic bacterium. A second factor, which can also be important, is growth on substrates that enter metabolism below the PFK level, such as lactate.

\section{RNA integrity and comparison of expression profiles}

Gene expression profiles were analysed by taking three RNA samples for each strain (HB-1+kanR and HB- 
$1+k a n R+p f k A)$. Steady-state duplicate RNA samples were taken from one chemostat and one RNA sample from a second chemostat (chemostat duplicate), giving a total of six RNA samples for two strains. The RNA integrity number scores (Schroeder et al., 2006) of the RNA samples ranged from 9.4 to 9.8 , indicating that the RNA was of good quality and suitable for use in DNA microarray analysis. This shows that the rapid sampling protocol used in this study followed by storage of the quenched biomass at $-80{ }^{\circ} \mathrm{C}$ prevents RNA degradation for a long period of time (at least 2 years). Gene expression correlation within the chemostat duplicates was high and similar to the correlation between the chemostat duplicates (all $R^{2}$ values were between 0.940 and 0.972 ). Therefore, all RNA samples from each strain were used as independent replicates during statistical analysis. The averaged gene expression differences indicate that the heterologous $p f k A$ gene is expressed in strain $\mathrm{HB}-1+k a n R+p f k A$. Introduction of the $p f k A$ gene in $N$. meningitidis induced a change in the gene expression level of the $p f k A$ gene $(F R=2.6, P=0.013)$ and high gene expression changes (FR $>3.7, P<0.003$ ) in the expression of only seven genes. These genes were upregulated in strain $\mathrm{HB}-1+k a n R+p f k A$ and include the pile gene (NMB0018) and six pils genes (NMB0020, NMB0021, NMB0022, NMB0023, NMB0025 and NMB0026). These virulence genes are phase-variable, i.e. are subject to reversible on/off switching of the expression state (Davidsen \& Tonjum, 2006). Therefore, it is possible that the 'on' expression state of these genes was selected during strain construction and that the upregulation of these genes is not the result of heterologous $p f k A$ expression. Hence, no large effects related to heterologous expression of $p f k A$ were observed in the transcriptome.

\section{Physiological and metabolic observations}

Successful expression of PFK in N. meningitidis HB$1+k a n R+p f k A$ was indicated by measuring the PFK activity in cell-free extracts using a coupling enzyme assay. In the $\mathrm{HB}-1+k a n R+p f k A$ cell lysate, the measured PFK activity was $440 \mathrm{U} \mathrm{l}^{-1}$. If it is assumed that all enzyme was liberated during the procedure to obtain cell-free extract, this translates into a specific PFK activity of $0.015 \mathrm{~mol}$ $(\mathrm{g} d \mathrm{dcw})^{-1} \mathrm{~h}^{-1}\left[0.353 \mu \mathrm{mol}(\mathrm{mg} \text { protein })^{-1} \mathrm{~min}^{-1}\right]$. Notably, this observed PFK activity was significantly lower (133-fold) than the measured PFK activity level in E. coli [47 $\mu \mathrm{mol}(\mathrm{mg} \text { protein })^{-1} \mathrm{~min}^{-1}$ ] grown in batch culture on LB medium (Ogawa et al., 2007). This may be due to the strength of the rmpM promoter, the presence of allosteric inhibitors as explained in the Introduction, or to active fructose-1,6-bisphosphatase in the N. meningitidis cell extract, which might interfere with the activity measurement (Uyeda \& Luby, 1974). Interference is unlikely in the E. coli cell extract, since fructose-1,6-bisphosphatase is not required for growth on hexoses and pentoses (Fraenkel \& Horecker, 1965).

The macromolecular biomass composition was determined on the two duplicate aerobic glucose-limited chemostat cultures and is shown in Table 1. In strain HB$1+k a n R+p f k A$, the RNA content was significantly higher and the LPS content lower, whereas no significant changes were observed for the other components. The cellular amino acid composition of the two strains did not differ significantly (Table 2). We observed small differences in fatty acid composition (Table 3). In particular, the unsaturated hexadecenoic acid $(\mathrm{C} 16: 1)$ content in strain HB- $1+k a n R+p f k A$ was somewhat higher, while the dodecanoic acid (C12:0), hydroxydodecanoic acid $(\mathrm{C} 12: 0-3 \mathrm{OH})$ and octadecanoic acid $(\mathrm{C} 18: 0)$ content was somewhat lower. Overall the changes in the biomass composition were minimal.

The redundancy matrix, expressing the redundancy relations between the measured exchange rates, was calculated for each individual dataset and contained a carbon and a nitrogen balance. The residuals obtained after multiplication of the redundancy matrix by the measured exchange rates could be explained on the basis of random measurement variances with test values that were lower than the $95 \%$ chi-squared critical value of 5.992 (van der Heijden et al., 1994). In addition, the individual carbon and nitrogen balances could be closed for all datasets. Hence, the carbon- and nitrogen-containing exchange rates were balanced.

The measured (balanced) C-mol yield of biomass on substrate, $\mathrm{Y}_{\mathrm{x} / \mathrm{s}}$, in strain $\mathrm{HB}-1+k a n R+p f k A$ was found to be $0.45 \pm 0.03 \mathrm{C}$-mol C-mol ${ }^{-1}$, while $\mathrm{Y}_{\mathrm{x} / \mathrm{s}}$ in strain HB$1+\operatorname{kan} R$ was found to be $0.52 \pm 0.03 \mathrm{C}-\mathrm{mol} \mathrm{C}-\mathrm{mol}^{-1}$. Notably, predictions obtained from in silico FBA, at the same growth rate of $0.13 \mathrm{~h}^{-1}$, indicated a small $\mathrm{Y}_{\mathrm{x} / \mathrm{s}}$

Table 1. Measured macromolecular composition (\%, w/w) of $N$. meningitidis strains $\mathrm{HB}-1+\operatorname{kan} R\left(p f k A^{-}\right)$and $\mathrm{HB}-1+$ $k a n R+p f k A\left(p f k A^{+}\right)($mean $\pm \mathrm{SD})$

\begin{tabular}{|lcc|}
\hline Component & $\boldsymbol{p} \boldsymbol{f} \boldsymbol{k} \boldsymbol{A}^{-}$ & $\boldsymbol{p} \boldsymbol{f} \boldsymbol{k} \boldsymbol{A}^{+}$ \\
\hline Protein & $67.14 \pm 7.85$ & $69.41 \pm 9.18$ \\
RNA & $5.87 \pm 1.47$ & $9.97 \pm 2.49$ \\
DNA & $1.79 \pm 0.27$ & $1.78 \pm 0.27$ \\
Phospholipids ${ }^{*}$ & $11.22 \pm 0.16$ & $10.69 \pm 0.14$ \\
LPS $\dagger$ & $5.83 \pm 0.16$ & $4.88 \pm 0.12$ \\
Peptidoglycan $\neq$ & $2.50 \pm 0.25$ & $2.50 \pm 0.25$ \\
Total & $94.3 \pm 8.0$ & $99.2 \pm 9.5$ \\
\hline
\end{tabular}

*The overall phospholipid composition used in the present study was based on the values provided by Rahman et al. (2000), including $11 \%$ phosphatidate (PA), $71 \%$ phosphatidylethanolamine (PE) and $18 \%$ phosphatidylglycerol (PG).

$\dagger$ LPS was quantified based on the measured amount of $\mathrm{C} 12: 0-3 \mathrm{OH}$ and possesses uncertainty (Baart et al., 2008).

$\ddagger$ Peptidoglycan in N. meningitidis was estimated based on E. coli (Neidhardt \& Umbarger, 1996), and the composition was based on the average of the peptidoglycan structures present in N. meningitidis (Antignac et al., 2003). For modelling purposes a relative mean standard deviation of $10 \%$ was assumed. 
Table 2. Measured cellular amino acid composition $(\%, w / w)$ of $N$. meningitidis strains $\mathrm{HB}-1+k a n R\left(p f k A^{-}\right)$and $\mathrm{HB}-$ $1+k a n R+p f k A\left(p f k A^{+}\right)(\operatorname{mean} \pm \mathrm{SD})$

\begin{tabular}{|lrc|}
\hline Component & $\boldsymbol{p} \boldsymbol{f k \boldsymbol { A } ^ { - }}$ & $\boldsymbol{p} \boldsymbol{f k \boldsymbol { A } ^ { + }}$ \\
\hline Aspartate & $5.68 \pm 0.26$ & $5.62 \pm 0.27$ \\
Glutamate & $7.78 \pm 0.43$ & $7.84 \pm 0.45$ \\
Serine & $3.79 \pm 0.19$ & $4.01 \pm 0.21$ \\
Histidine & $2.13 \pm 0.14$ & $2.05 \pm 0.16$ \\
Glycine & $5.45 \pm 0.27$ & $5.51 \pm 0.28$ \\
Threonine & $4.64 \pm 0.21$ & $4.46 \pm 0.20$ \\
Alanine & $8.75 \pm 0.40$ & $9.14 \pm 0.42$ \\
Arginine & $7.85 \pm 0.33$ & $8.05 \pm 0.35$ \\
Tyrosine & $3.72 \pm 0.14$ & $3.91 \pm 0.15$ \\
Valine & $6.6 \pm 0.32$ & $6.59 \pm 0.30$ \\
Methionine & $2.67 \pm 0.15$ & $2.57 \pm 0.21$ \\
Phenylalanine & $4.54 \pm 0.16$ & $4.45 \pm 0.17$ \\
Isoleucine & $5.11 \pm 0.22$ & $5.08 \pm 0.22$ \\
Leucine & $8.32 \pm 0.32$ & $8.16 \pm 0.33$ \\
Lysine & $6.96 \pm 1.11$ & $6.88 \pm 1.16$ \\
Proline & $3.72 \pm 0.31$ & $3.64 \pm 0.30$ \\
Asparagine & $4.35 \pm 0.23$ & $4.31 \pm 0.24$ \\
Tryptophan & $1.98 \pm 0.54$ & $1.91 \pm 0.54$ \\
Cysteine & $0.96 \pm 0.33$ & $0.83 \pm 0.32$ \\
Glutamine & $4.97 \pm 0.39$ & $5.00 \pm 0.41$ \\
& & \\
\hline
\end{tabular}

increase for strain HB-1 $+k a n R+p f k A$. This might explain why the $p f k A$ gene is not obtained by HGT, since it is initially unfavourable for biomass yield. The lower $\mathrm{Y}_{\mathrm{x} / \mathrm{s}}$ in strain $\mathrm{HB}-1+k a n R+p f k A$ means that less carbon is assimilated in biomass, which was compensated mainly by an increase in $\mathrm{CO}_{2}$ production (i.e. $0.52 \pm 0.06 \mathrm{C}$-mol $\mathrm{C}-\mathrm{mol}^{-1}$ for strain HB-1 $+k a n R+p f k A$ and $0.44 \pm 0.04 \mathrm{C}-$ mol C-mol ${ }^{-1}$ for strain HB-1+kanR), while the production of by-products (i.e. ethanol, acetate, acetahldehyde, lactate, amino acids and proteins) was low and similar in the two strains (i.e. $0.03 \pm 0.01 \mathrm{C}-\mathrm{mol} \mathrm{C}-\mathrm{mol}^{-1}$ for strain $\mathrm{HB}-1+k a n R+p f k A$ and $0.05 \pm 0.01 \mathrm{C}-\mathrm{mol} \mathrm{C}-\mathrm{mol}^{-1}$ for strain $\mathrm{HB}-1+k a n R)$.
As explained in Methods, a single solution for the underdetermined parts (see Supplementary Material, model worksheet) of both metabolic networks was calculated using maximization of ATP yield (maxATP) as an objective function. Both the ED pathway and the EMP pathway are underdetermined, which means that the calculated fluxes for these parts are determined by the objective function. Due to the thiosulfate conversion reaction (reaction 51 in the model), the oxidative phosphorylation reaction (reaction 71 in the model) is also underdetermined. However, based on the thiosulfate concentration in the medium $(0.38 \mathrm{mM})$, we calculate that the maximum oxygen consumption rate for this reaction is less than $1 \%$ of the measured oxygen consumption rate, which means that the measured oxygen consumption rate determines the rate of the oxidative phosphorylation reaction and therefore ATP production from this source. It was found that in the HB-1+kanR+pfkA strain, $24 \%$ of the total ATP was formed in the EMP pathway, the citric acid cycle and the acetate production reaction, whereas in the HB- $1+k a n R$ strain, $16 \%$ of the total ATP was formed in the ED pathway, the citric acid cycle and the acetate production reaction. In both strains, the remainder of the ATP was formed by oxidative phosphorylation (see Supplementary data, flux distributions worksheet). As expected, using this objective function, the HB-1+kanR strain processes glucose 6-phosphate solely through the ED pathway, since the ED pathway can yield slightly more energy per molecule of glucose consumed than the PP pathway (Baart et al., 2008). It was found that the ATP hydrolysis flux (i.e. the flux that was maximized) was twice as high in the HB-1+kanR+pfkA strain (see Supplementary data, flux distributions worksheet). Even if it is assumed that the EMP pathway is not active in the PFK-positive strain due to a PFK activity that is too low, and that glucose is metabolized through the ED pathway, the ATP hydrolysis flux is still 1.6 times higher in the PFKpositive strain. This means that in the PFK-positive strain more ATP is produced, which is directly related to the higher oxygen consumption measured for this strain. The

Table 3. Measured cellular fatty acid composition (\%, w/w) of $N$. meningitidis strains $\mathrm{HB}-1+k a n R\left(p f k A^{-}\right)$ and $\mathrm{HB}-1+k a n R+p f k A\left(p f k A^{+}\right)($mean $\pm \mathrm{SD})$

\begin{tabular}{|c|c|c|}
\hline Component & $p f k A^{-}$ & $p f k A^{+}$ \\
\hline Dodecanoic acid $(\mathrm{C} 12: 0)$ & $7.99 \pm 0.33$ & $6.93 \pm 0.33$ \\
\hline 3-Hydroxydodecanoic acid (C12:0-3OH) & $7.54 \pm 0.26$ & $6.83 \pm 0.24$ \\
\hline 3-Hydroxytetradecanoic acid $(\mathrm{C} 14: 0-3 \mathrm{OH})^{*}$ & $3.31 \pm 0.27$ & $3.50 \pm 0.12$ \\
\hline Tetradecanoic acid $(\mathrm{C} 14: 0)$ & $8.53 \pm 0.26$ & $7.72 \pm 0.25$ \\
\hline Hexadecenoic acid (C16:1 trans-9) & $20.92 \pm 0.83$ & $23.29 \pm 0.75$ \\
\hline Hexadecenoic acid (C16:1 $\omega-7$-cis) & $0.40 \pm 0.02$ & $0.46 \pm 0.02$ \\
\hline Hexadecanoic acid $(\mathrm{C} 16: 0)$ & $39.53 \pm 1.4$ & $38.98 \pm 1.43$ \\
\hline Octadecenoic acid (C18:1 $\omega-7-c i s)$ & $10.52 \pm 0.44$ & $11.40 \pm 0.72$ \\
\hline Octadecanoic acid $(\mathrm{C} 18: 0)$ & $1.26 \pm 0.06$ & $0.89 \pm 0.06$ \\
\hline
\end{tabular}

${ }^{*}$ The $\mathrm{C} 14: 0-3 \mathrm{OH}$ quantity was calculated from the corresponding measured $\mathrm{C} 12: 0-3 \mathrm{OH}$ quantity, as explained previously (Baart et al., 2008). 
expected effect on biomass yield due to the extra ATP produced is abolished by an ATP-consuming process, which can be stress, protein turnover or futile cycling in combination with fructose bisphosphatase, resulting in the loss of ATP. To compensate for this, more ATP must be generated from glucose, resulting in more $\mathrm{O}_{2}$ consumption and $\mathrm{CO}_{2}$ generation, and a decrease in biomass yield. The biomass composition of both strains is similar, which indicates that it is unlikely that more ATP is required for HB- $1+k a n R+p f k A$ biomass formation. Notably, the measured PFK activity in the HB-1+kanR+pfkA strain is sufficient to explain the additional ATP turnover and the calculated PFK flux. In the HB-1+kanR+pfkA strain, the calculated PFK flux is $0.002 \mathrm{~mol} \mathrm{~g}^{-1} \mathrm{~h}^{-1}$ and the increase in the ATP hydrolysis reaction upon PFK introduction is $0.008 \mathrm{~mol} \mathrm{~g}^{-1} \mathrm{~h}^{-1}$ (see Supplementary data, flux distributions worksheet). If we assume that this additional ATP hydrolysis is caused by futile cycling through PFK and phosphatase, then the total PFK flux is $0.01 \mathrm{~mol} \mathrm{~g}^{-1} \mathrm{~h}^{-1}$, which is $32 \%$ lower than the measured specific PFK activity $\left(0.015 \mathrm{~mol} \mathrm{~g}^{-1} \mathrm{~h}^{-1}\right)$ in the HB-1+kanR+pfkA strain and shows that the calculated flux is feasible. Hence, futile cycling upon introduction of $p f k A$ in $N$. meningitidis seems the most plausible ATP-consuming process.

No significant differences between the maximum growth rates of the two strains were observed during the batch phase preceding the chemostat phase (results not shown). Theoretically, a higher yield would be expected, and due to the above-mentioned trade off between high biomass yield and high energy dissipation rates a lower maximum growth rate would be expected. As a result of futile cycling, ATP is lost (and energy is dissipated), more $\mathrm{CO}_{2}$ is produced and a lower yield of biomass on substrate is found. The extra dissipation of energy may explain why a lower growth rate was not found, which is thus in line with the theory. Adaptive evolution to achieve a robust, optimal metabolic network that enables a higher growth rate (Hua et al., 2007) or a higher yield might be possible.

\section{Conclusions}

The phylogenetic distribution of PFK indicates that it is lacking in most obligate aerobic organisms. In many (facultative) anaerobic organisms, PFK is present and goes hand in hand with the presence of a PTS system. A competitive advantage under anaerobic conditions seems to be the most important factor for the presence of PFK. In the case of limiting energy availability due to the absence of oxidative phosphorylation, the objective of an organism seems to be to optimize the yield of energy on substrate (maximize $\mathrm{Y}_{\mathrm{ATP} / \mathrm{s}}$ ), favouring PFK. In the case when sufficient energy can be liberated from the substrate by oxidative phosphorylation, the objective of an organism seems to be to optimize the rate of energy generation (maximize $\mathrm{r}_{\mathrm{ATP}}$ ) in order to outcompete other microorganisms living in the same habitat. Since the natural evolution of $N$. meningitidis takes place in the aerobic nasopharyngeal mucosa, the absence of $p f k A$ in the $N$. meningitidis genome can be explained. In silico FBA predicts an increase in biomass yield upon inclusion of PFK. However, experimentally, a lower biomass yield is found in the presence of PFK than in the control strain without PFK. We hypothesize that this is caused by active phosphatases, creating futile cycles and the dissipation of energy. This makes it clear that no initial advantage is gained when PFK is expressed in N. meningitidis, which indicates that possible HGT events to obtain the $p f k A$ gene are unlikely.

\section{ACKNOWLEDGEMENTS}

We thank Jeroen Pennings for his help with the microarray analysis and data processing, Marieke Willemsen, Elly Verhagen and Jan van den Ijssel for practical assistance, Alex de Haan for HPLC and GC measurements, Martin Hamzink for NMR measurements, Marcel Hoefnagel for sharing his knowledge of the determination of phosphofructokinase activity in cell-free extracts, Jo Maertens for his work on sequence analysis and Christoph Schoen for sharing his view on this subject. We also acknowledge the Gonococcal Genome Sequencing Project, and B. A. Roe, S. P. Lin, L. Song, X. Yuan, S. Clifton and D. W. Dyer, supported by USPHS/NIH grant \#AI38399.

\section{REFERENCES}

Antignac, A., Rousselle, J. C., Namane, A., Labigne, A., Taha, M. K. \& Boneca, I. G. (2003). Detailed structural analysis of the peptidoglycan of the human pathogen Neisseria meningitidis. J Biol Chem 278, 31521-31528.

Baart, G. J., Zomer, B., de Haan, A., van der Pol, L. A., Beuvery, E. C., Tramper, J. \& Martens, D. E. (2007a). Modeling Neisseria meningitidis metabolism: from genome to metabolic fluxes. Genome Biol 8, R136.

Baart, G. J. E., de Jong, G., Philippi, M., Riet, K. V. T., van der Pol, L. A., Beuvery, E. C., Tramper, J. \& Martens, D. E. (2007b). Scale-up for bulk production of vaccine against meningococcal disease. Vaccine 25, 6399-6408.

Baart, G. J. E., Willemsen, M., Khatami, E., de Haan, A., Zomer, B., Beuvery, E. C., Tramper, J. \& Martens, D. E. (2008). Modeling Neisseria meningitidis B metabolism at different specific growth rates. Biotechnol Bioeng 101, 1022-1035.

Bapteste, E., Moreira, D. \& Philippe, H. (2003). Rampant horizontal gene transfer and phospho-donor change in the evolution of the phosphofructokinase. Gene 318, 185-191.

Bartolini, E., Frigimelica, E., Giovinazzi, S., Galli, G., Shaik, Y., Genco, C., Welsch, J. A., Granoff, D. M., Grandi, G. \& Grifantini, R. (2006). Role of FNR and FNR-regulated, sugar fermentation genes in Neisseria meningitidis infection. Mol Microbiol 60, 963-972.

Bentley, S. D., Vernikos, G. S., Snyder, L. A., Churcher, C., Arrowsmith, C., Chillingworth, T., Cronin, A., Davis, P. H., Holroyd, N. E. \& other authors (2007). Meningococcal genetic variation mechanisms viewed through comparative analysis of serogroup $\mathrm{C}$ strain FAM18. PLoS Genet 3, e23.

Blangy, D., Buc, H. \& Monod, J. (1968). Kinetics of the allosteric interactions of phosphofructokinase from Escherichia coli. J Mol Biol 31, 13-35.

Bos, M. P. \& Tommassen, J. (2005). Viability of a capsule- and lipopolysaccharide-deficient mutant of Neisseria meningitidis. Infect Immun 73, 6194-6197. 
Brauer, M. J., Saldanha, A. J., Dolinski, K. \& Botstein, D. (2005). Homeostatic adjustment and metabolic remodeling in glucoselimited yeast cultures. Mol Biol Cell 16, 2503-2517.

Davidsen, T. \& Tonjum, T. (2006). Meningococcal genome dynamics. Nat Rev Microbiol 4, 11-22.

Deutscher, J., Francke, C. \& Postma, P. W. (2006). How phosphotransferase system-related protein phosphorylation regulates carbohydrate metabolism in bacteria. Microbiol Mol Biol Rev 70, 9391031.

Dorresteijn, R. C., de Gooijer, C. D., Tramper, J. \& Beuvery, E. C. (1994). A method for simultaneous determination of solubility and transfer coefficient of oxygen in aqueous media using off-gas mass spectrometry. Biotechnol Bioeng 43, 149-154.

Edwards, J. S., Ramakrishna, R., Schilling, C. H. \& Palsson, B. O. (1999). Metabolic flux balance analysis. In Metabolic Engineering, pp. 13 57. Edited by S. Y. Lee \& E. T. Papoutsakis. New York: Marcel Dekker.

Edwards, J. S., Ibarra, R. U. \& Palsson, B. O. (2001). In silico predictions of Escherichia coli metabolic capabilities are consistent with experimental data. Nat Biotechnol 19, 125-130.

Elkins, C., Thomas, C. E., Seifert, H. S. \& Sparling, P. F. (1991). Species-specific uptake of DNA by gonococci is mediated by a 10 base-pair sequence. J Bacteriol 173, 3911-3913.

Exley, R. M., Shaw, J., Mowe, E., Sun, Y. H., West, N. P., Williamson, M., Botto, M., Smith, H. \& Tang, C. M. (2005). Available carbon source influences the resistance of Neisseria meningitidis against complement. J Exp Med 201, 1637-1645.

Flores, N., Flores, S., Escalante, A., de Anda, R., Leal, L., Malpica, R., Georgellis, D., Gosset, G. \& Bolivar, F. (2005). Adaptation for fast growth on glucose by differential expression of central carbon metabolism and gal regulon genes in an Escherichia coli strain lacking the phosphoenolpyruvate: carbohydrate phosphotransferase system. Metab Eng 7, 70-87.

Fordyce, A. M., Moore, C. H. \& Pritchard, G. G. (1982). Phosphofructokinase from Streptococcus lactis. Methods Enzymol 90, 77-82.

Forster, J., Gombert, A. K. \& Nielsen, J. (2002). A functional genomics approach using metabolomics and in silico pathway analysis. Biotechnol Bioeng 79, 703-712.

Fraenkel, D. G. (1996). Glycolysis. In Escherichia coli and Salmonella typhimurium: Cellular and Molecular Biology, pp. 189-198. Edited by F. C. Neidhardt, R. Curtiss, J. L. Ingraham, K. Brooks Low, B. Magasanik, W. S. Reznikoff, M. Riley, M. Schaechter \& H. E. Umbarger. Washington DC: American Society for Microbiology.

Fraenkel, D. G. \& Horecker, B. L. (1965). Fructose-1,6-diphosphatase and acid hexose phosphatase of Escherichia coli. J Bacteriol 90, 837842.

Girard, M. P., Preziosi, M. P., Aguado, M. T. \& Kieny, M. P. (2006). A review of vaccine research and development: meningococcal disease. Vaccine 24, 4692-4700.

Guixe, V. \& Babul, J. (1985). Effect of ATP on phosphofructokinase-2 from Escherichia coli. A mutant enzyme altered in the allosteric site for MgATP. J Biol Chem 260, 11001-11005.

Holten, E. (1974). 6-Phosphogluconate dehydrogenase and enzymes of the Entner-Doudoroff pathway in Neisseria. Acta Pathol Microbiol Scand B Microbiol Immunol 82, 207-213.

Holten, E. (1975). Radiorespirometric studies in genus Neisseria. I. The catabolism of glucose. Acta Pathol Microbiol Scand [B] 83, 353366.

Hua, Q., Joyce, A. R., Palsson, B. O. \& Fong, S. S. (2007). Metabolic characterization of Escherichia coli strains adapted to growth on lactate. Appl Environ Microbiol 73, 4639-4647.
Ito, S., Fushinobu, S., Yoshioka, I., Koga, S., Matsuzawa, H. \& Wakagi, T. (2001). Structural basis for the ADP-specificity of a novel glucokinase from a hyperthermophilic archaeon. Structure 9, 205214.

Jyssum, K. (1962a). Dissimilation of $\mathrm{C}^{14}$ labelled glucose by Neisseria meningitidis 2. The incorporation of $1-C^{14}$ and $6-C^{14}$ into pyruvate. Acta Pathol Microbiol Immunol Scand [B] 55, 335-341.

Jyssum, K. (1962b). Dissimilation of $\mathrm{C}^{14}$ labelled glucose by Neisseria meningitidis 1. The formation of $\mathrm{CO}_{2}$ and acetate from glucose carbon. Acta Pathol Microbiol Immunol Scand [B] 55, 319-324.

Jyssum, K. (1962c). Dissimilation of $C^{14}$ labelled glucose by Neisseria meningitidis 2 . The incorporation of $1-C^{14}$ and $6-C^{14}$ into cellular components in short time experiments. Acta Pathol Microbiol Immunol Scand $[B]$ 55, 325-334.

Jyssum, K., Borchgrevink, B. \& Jyssum, S. (1961). Glucose catabolism in Neisseria meningitidis. 1. Glucose oxidation and intermediate reactions of the Embden-Meyerhof pathway. Acta Pathol Microbiol Scand 53, 71-83.

Kroll, J. S., Wilks, K. E., Farrant, J. L. \& Langford, P. R. (1998). Natural genetic exchange between Haemophilus and Neisseria: intergeneric transfer of chromosomal genes between major human pathogens. Proc Natl Acad Sci U S A 95, 12381-12385.

Lange, H. C. \& Heijnen, J. J. (2001). Statistical reconciliation of the elemental and molecular biomass composition of Saccharomyces cerevisiae. Biotechnol Bioeng 75, 334-344.

Lange, H. C., Eman, M., van Zuijlen, G., Visser, D., van Dam, J. C., Frank, J., de Mattos, M. J. \& Heijnen, J. J. (2001). Improved rapid sampling for in vivo kinetics of intracellular metabolites in Saccharomyces cerevisiae. Biotechnol Bioeng 75, 406-415.

Liu, J.-S., Vojinovic, V., Patino, R., Maskow, T. \& von Stockar, U. (2007). A comparison of various Gibbs energy dissipation correlations for predicting microbial growth yields. Thermochim Acta 458, 38-46.

Muller, M., Lee, J. A., Gordon, P., Gaasterland, T. \& Sensen, C. W. (2001). Presence of prokaryotic and eukaryotic species in all subgroups of the $\mathrm{PP}_{\mathrm{i}}$-dependent group II phosphofructokinase protein family. J Bacteriol 183, 6714-6716.

Nassif, X., Pujol, C., Morand, P. \& Eugene, E. (1999). Interactions of pathogenic Neisseria with host cells. Is it possible to assemble the puzzle? Mol Microbiol 32, 1124-1132.

Neidhardt, F. C. \& Umbarger, H. E. (1996). Chemical composition of Escherichia coli. In Escherichia coli and Salmonella typhimurium: Cellular and Molecular Biology, pp. 13-16. Edited by F. C. Neidhardt, R. Curtiss, J. L. Ingraham, K. Brooks Low, B. Magasanik, W. S. Reznikoff, M. Riley, M. Schaechter \& H. E. Umbarger. Washington DC: American Society for Microbiology.

Ogawa, T., Mori, H., Tomita, M. \& Yoshino, M. (2007). Inhibitory effect of phosphoenolpyruvate on glycolytic enzymes in Escherichia coli. Res Microbiol 158, 159-163.

Omelchenko, M. V., Makarova, K. S., Wolf, Y. I., Rogozin, I. B. \& Koonin, E. V. (2003). Evolution of mosaic operons by horizontal gene transfer and gene displacement in situ. Genome Biol 4, R55.

Parkhill, J., Achtman, M., James, K. D., Bentley, S. D., Churcher, C., Klee, S. R., Morelli, G., Basham, D., Brown, D. \& other authors (2000). Complete DNA sequence of a serogroup A strain of Neisseria meningitidis Z2491. Nature 404, 502-506.

Peng, J., Yang, L., Yang, F., Yang, J., Yan, Y., Nie, H., Zhang, X., Xiong, Z., Jiang, Y. \& other authors (2008). Characterization of ST-4821 complex, a unique Neisseria meningitidis clone. Genomics 91, 78-87.

Postma, E., Verduyn, C., Scheffers, W. A. \& Van Dijken, J. P. (1989). Enzymic analysis of the Crabtree effect in glucose-limited chemostat cultures of Saccharomyces cerevisiae. Appl Environ Microbiol 55, 468477. 
Postma, P. W., Lengeler, J. W. \& Jacobson, G. R. (1993). Phosphoenolpyruvate: carbohydrate phosphotransferase systems of bacteria. Microbiol Rev 57, 543-594.

Rahman, M. M., Kolli, V. S., Kahler, C. M., Shih, G., Stephens, D. S. \& Carlson, R. W. (2000). The membrane phospholipids of Neisseria meningitidis and Neisseria gonorrhoeae as characterized by fast atom bombardment mass spectrometry. Microbiology 146, 1901-1911.

Rosenstein, N. E., Perkins, B. A., Stephens, D. S., Popovic, T. \& Hughes, J. M. (2001). Meningococcal disease. N Engl J Med 344, 1378-1388.

Sambrook, J., Fritsch, E. F. \& Maniatis, T. (1989). Molecular Cloning: a Laboratory Manual, 2nd edn. Cold Spring Harbor, NY: Cold Spring Harbor Laboratory.

Schroeder, A., Mueller, O., Stocker, S., Salowsky, R., Leiber, M., Gassmann, M., Lightfoot, S., Menzel, W., Granzow, M. \& Ragg, T. (2006). The RIN: an RNA integrity number for assigning integrity values to RNA measurements. BMC Mol Biol 7, 3.

Schuetz, R., Kuepfer, L. \& Sauer, U. (2007). Systematic evaluation of objective functions for predicting intracellular fluxes in Escherichia coli. Mol Syst Biol 3, 119.

Seifert, H. S., Ajioka, R. S., Marchal, C., Sparling, P. F. \& So, M. (1988). DNA transformation leads to pilin antigenic variation in Neisseria gonorrhoeae. Nature 336, 392-395.

Siebers, B., Klenk, H. P. \& Hensel, R. (1998). $\mathrm{PP}_{\mathrm{i}}$-dependent phosphofructokinase from Thermoproteus tenax, an archaeal descendant of an ancient line in phosphofructokinase evolution. J Bacteriol 180, 2137-2143.

Spratt, B. G., Bowler, L. D., Zhang, Q. Y., Zhou, J. \& Smith, J. M. (1992). Role of interspecies transfer of chromosomal genes in the evolution of penicillin resistance in pathogenic and commensal Neisseria species. J Mol Evol 34, 115-125.

Stephens, D. S., Hoffman, L. H. \& McGee, Z. A. (1983). Interaction of Neisseria meningitidis with human nasopharyngeal mucosa: attachment and entry into columnar epithelial cells. J Infect Dis 148, 369-376.

Tettelin, H., Saunders, N. J., Heidelberg, J., Jeffries, A. C., Nelson, K. E., Eisen, J. A., Ketchum, K. A., Hood, D. W., Peden, J. F. \& other authors (2000). Complete genome sequence of Neisseria meningitidis serogroup B strain MC58. Science 287, 1809-1815.

Trotter, C. L. \& Ramsay, M. E. (2007). Vaccination against meningococcal disease in Europe: review and recommendations for the use of conjugate vaccines. FEMS Microbiol Rev 31, 101-107.

Uyeda, K. \& Luby, L. J. (1974). Studies on the effect of fructose diphosphatase on phosphofructokinase. J Biol Chem 249, 4562-4570.
Vallino, J. J. \& Stephanopoulos, G. (1990). Flux determination in cellular bioreaction networks: applications to lysine fermentations. In Frontiers in Bioprocessing, pp. 205-219. Edited by S. K. Sikdar, M. Bier \& P. Todd. Boca Raton, FL: CRC Press.

van der Heijden, R. T. J. M., Romein, B., Heijnen, J. J., Hellinga, C. \& Luyben, K. C. A. M. (1994). Linear constraint relations in biochemical reaction systems: II. Diagnosis and estimation of gross errors. Biotechnol Bioeng 43, 11-20.

van der Ley, P. \& van Alphen, L. (2001). Construction of porA mutants. In Meningococcal Vaccines, pp. 145-154. Totowa, NJ: Humana Press.

van der Ley, P., van der Biezen, J., Hohenstein, P., Peeters, C. \& Poolman, J. T. (1993). Use of transformation to construct antigenic hybrids of the class 1 outer membrane protein in Neisseria meningitidis. Infect Immun 61, 4217-4224.

van der Ley, P., van der Biezen, J. \& Poolman, J. T. (1995). Construction of Neisseria meningitidis strains carrying multiple chromosomal copies of the porA gene for use in the production of a multivalent outer membrane vesicle vaccine. Vaccine 13, 401-407.

van Gulik, W. M. \& Heijnen, J. J. (1995). A metabolic network stoichiometry analysis of microbial growth and product formation. Biotechnol Bioeng 48, 681-698.

Verhees, C. H., Tuininga, J. E., Kengen, S. W., Stams, A. J., van der Oost, J. \& de Vos, W. M. (2001). ADP-dependent phosphofructokinases in mesophilic and thermophilic methanogenic archaea. J Bacteriol 183, 7145-7153.

von Mering, C., Jensen, L. J., Snel, B., Hooper, S. D., Krupp, M., Foglierini, M., Jouffre, N., Huynen, M. A. \& Bork, P. (2005). STRING: known and predicted protein-protein associations, integrated and transferred across organisms. Nucleic Acids Res 33, D433-D437.

von Stockar, U., Maskow, T., Liu, J., Marison, I. W. \& Patino, R. (2006). Thermodynamics of microbial growth and metabolism: an analysis of the current situation. J Biotechnol 121, 517-533.

Vulic, M. \& Kolter, R. (2001). Evolutionary cheating in Escherichia coli stationary phase cultures. Genetics 158, 519-526.

Zhou, J. \& Spratt, B. G. (1992). Sequence diversity within the $\arg F, f b p$ and $r e c A$ genes of natural isolates of Neisseria meningitidis: interspecies recombination within the $\operatorname{argF}$ gene. Mol Microbiol 6, $2135-2146$.

Zimmer, S. M. \& Stephens, D. S. (2006). Serogroup B meningococcal vaccines. Curr Opin Investig Drugs 7, 733-739.

Edited by: J. Moir 